Volume 10, No.4, July - August 2021

International Journal of Advanced Trends in Computer Science and Engineering

Available Online at http://www.warse.org/IJATCSE/static/pdf/file/ijatcse201042021.pdf

https://doi.org/10.30534/ijatcse/2021/201042021

\title{
Machine design of Roselle Seed Ripping Machine through Design of Experiment
}

\author{
T. Kriangkrai ${ }^{1}$, B. Surapong ${ }^{2}$, C. Kijcha ${ }^{3}$ and S. Khongsak ${ }^{4}$ \\ ${ }^{1}$ Faculty of Engineering, Rajamangala University of Technology Lanna, Chiangmai, Thailand, k.kriang1964@ gmailmail.com \\ ${ }^{2}$ Faculty of Engineering, Rajamangala University of Technology Lanna, Chiangmai, Thailand, pong_pang49@yahoo.com \\ ${ }^{3}$ Faculty of Engineering, Rajamangala University of Technology Lanna, Chiangmai, Thailand, kitchar@ $@$ rmutl.ac.th \\ ${ }^{4}$ Faculty of Business administration, Thai-Nichi Institute of Technology, Bangkok, Thailand, khongsaksss67@gmail.com
}

\begin{abstract}
The objective of this research is to reduce waste of the roselle seed ripping machine by using the design of experiment (DOE) method. Three parameters could be observed which are the air pressure, degree of rotation and type of knife. Therefore, it is desirable to see the effects of all parameters in good yield. In this paper, a series of experiment has been carried accordingly to the design of experiment order. Later, ANalysis Of Variance (ANOVA) is performed in order to investigate the most significant parameter for the good yield of the roselle seed ripping production. Our result shows that the air pressure of cylinder plays the most significant role with zero P-value while the degree of rotation and type of knife parameters are larger than the confident level, $\alpha$.
\end{abstract}

Key words: design of experiment, productivity improvement, waste reduction, roselle seed ripping, randomize

\section{INTRODUCTION}

In the present, every organization must continually improve their production in order to survive the business as well as being able to compete with competitors in the market. The key factors that contribute to a successful business are producing reliable quality products and low production cost. Therefore, the improvement and study of factors affecting costs in the production process is another activity that organizations should not be overlooked. Roselle is an important agricultural crop of Thailand. Because roselle is popular, the petals of the flower can be made into a drink. Workers take fresh roselle flowers and separate the seeds from the petals by stabbing with a pointed device. Then the roselle petals will be dried in the sun before being packaged for further sale.

Roselle seed ripping machine is used to increase production capacity. Researchers have designed a prototype machine that can run much faster than manual labour. The design of the machine directly plays an important role in the quality of the product and affect the production cost. Therefore, it's necessary to determine the variables that directly affect good quantity produced by the use of this prototype machine in production, design of experiment techniques have been used. Experimental design techniques[1] are widely used to reduce waste from production[2], finding the best production conditions[3], [4], design for ergonomic[5], design for the best service jobs[6], [7], quality improvement [8], combine the production processes[9] and improvement the manufacturing processes[10].

\section{CURRENT SITUATION}

Figure1, when the roselle is 180 days old, it can be gradually collected until the plant is gone by choosing to cut the large flowers first. Yields dry petals about $180-200$ kilograms / 1,600 square meters.

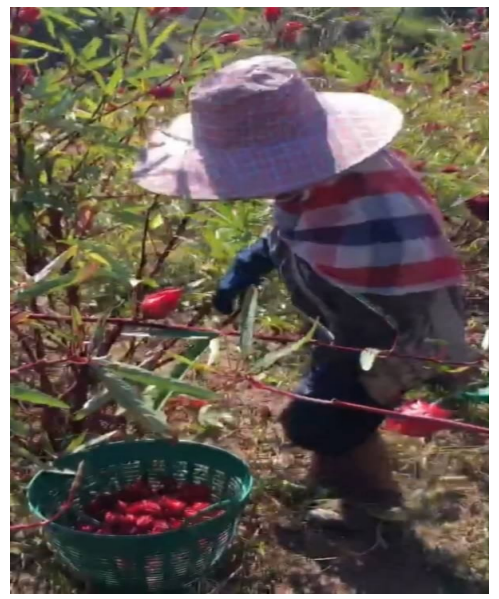

Figure 1: Farmers collects large and mature roselle flowers

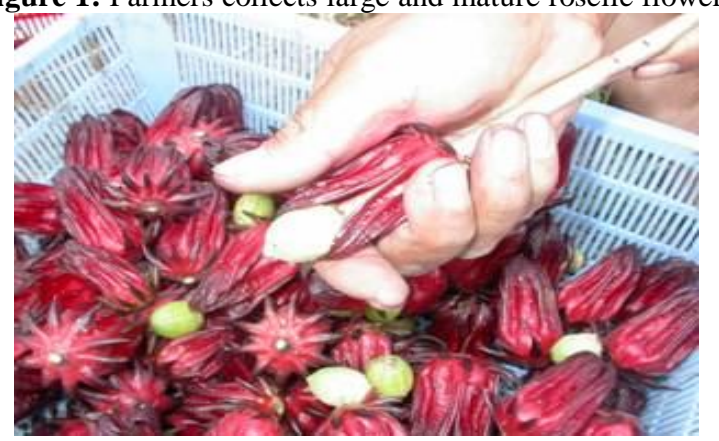

Figure 2: Manual ripping 
The seeds are ejected from the flower by using an umbrella rod. Figure 2 presented the workers do this for all flowers before they are washed. With this production method, although the yield is high because the workers can adjust the ripping method to suit the size of each roselle flower. But there is a limitation that the amount of production will be very low. Too late production will cause the roselle flowers to rot.

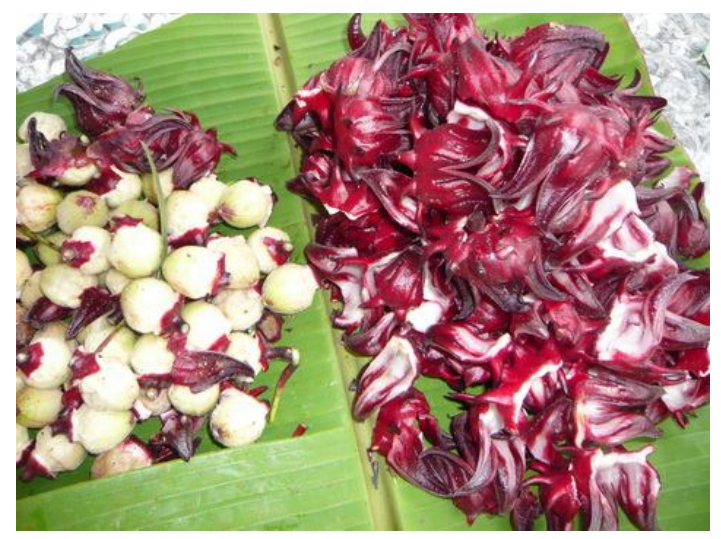

Figure 3: results after seed separation

Petals with seeds removed presented in figure 3 will be cleaned. Then it will be placed in the sun to dry around 3-7 days. Then do the packing ready for distribution.

\section{PROTOTYPE OF ROSELLE SEED RIPPING MACHINE}

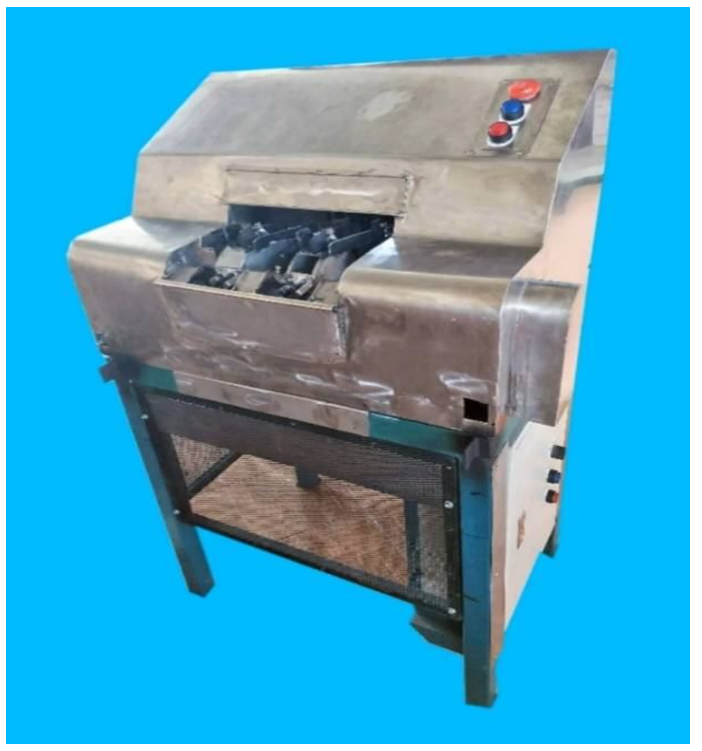

Figure 4: Prototype machine

A compact prototype presented in figure4 it can be moved easily, suitable for use in farming areas where electricity is available. The production capacity is 10 times greater than that of manual labour, as two seeds can be rammed at a time in just 2 seconds, while manual production takes an average of 10 seconds per piece. With such a high production rate, it has attracted great attention to agriculture. However, the good rate is something that needs to be analysed further.

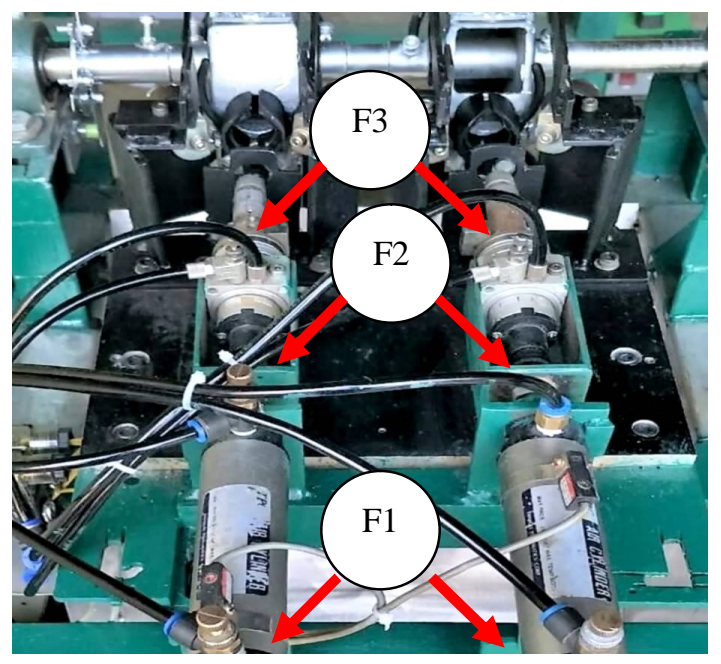

Figure 5: Location of equipment

Figure 5 shows the location of the variable device. F1 is cylinder. The air pressure applied to the test cylinder causes the thrust force acting on the roselle seeds. F2 is the rotation cylinder. The air pressure supplied to the cylinder allows the thrust head to rotate 90 degrees. When there is no air supply, the thrust head will turn back to its original position. F3 is knife. There are two types of knifes using in this research, pointed type and round type.

\section{DESIGN OF EXPERIMENT}

\subsection{Measurement Methods}

Standard Order for a $2^{\mathrm{k}}$ Level Factorial Design, consider the two-level, full factorial design for three factors, namely the $2^{3}$ designs. This implies 16 runs (with one replication). Graphically, we can represent the $2^{3}$ designs by the cube shown in figure 6 . The arrows show the direction of increase of the factors. The numbers " 1 " through " 8 " at the corners of the design box reference the "Standard Order" of runs.

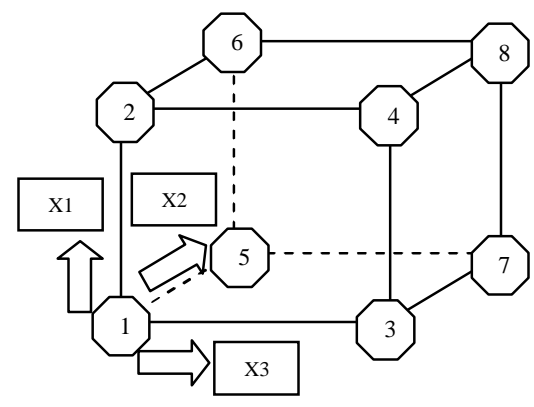

Figure 6: Standard Order for a $2^{\mathrm{k}}$ Level Factorial Design 
Table 1: The Randomized Measurement Order, with Air pressure, Degree of rotation, Type of knife.

\begin{tabular}{|c|c|c|c|}
\hline $\begin{array}{c}\text { Run } \\
\text { Order }\end{array}$ & $\begin{array}{c}\text { Air pressure } \\
\text { (Bar) }\end{array}$ & $\begin{array}{c}\text { Degree of } \\
\text { rotation }\end{array}$ & $\begin{array}{c}\text { Type of } \\
\text { knife }\end{array}$ \\
\hline 1 & 2 & 0 & Pointed \\
\hline 2 & 1 & 0 & Pointed \\
\hline 3 & 1 & 0 & Round \\
\hline 4 & 1 & 0 & Round \\
\hline 5 & 2 & 90 & Round \\
\hline 6 & 2 & 0 & Pointed \\
\hline 7 & 1 & 90 & Pointed \\
\hline 8 & 2 & 0 & Round \\
\hline 9 & 2 & 90 & Pointed \\
\hline 10 & 1 & 90 & Pointed \\
\hline 11 & 2 & 90 & Pointed \\
\hline 12 & 1 & 0 & Pointed \\
\hline 13 & 1 & 90 & Round \\
\hline 14 & 2 & 90 & Round \\
\hline 15 & 2 & 0 & Round \\
\hline 16 & 1 & 90 & Round \\
\hline
\end{tabular}

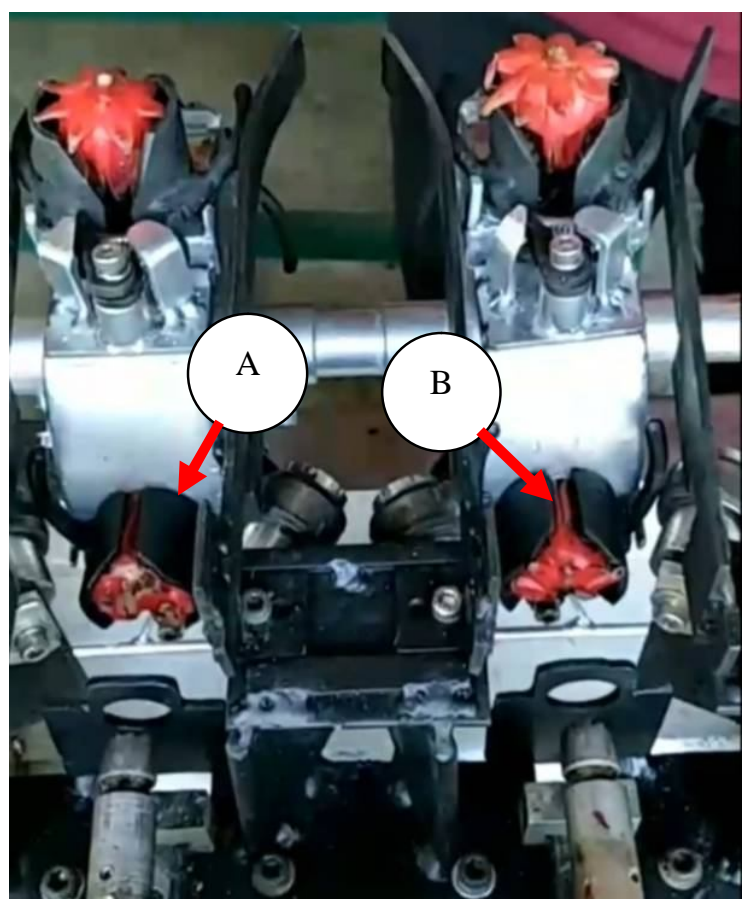

Figure 7: Judgment on outcome A, B

By using the Minitab ${ }^{\circledR}$ software, the experiment table is automatically generated for full factorial design with randomization. Air pressure, degree of rotation and type of knife are the investigated factors of the DoE in order to evaluate their effects on the rate of good pieces. The two air pressure treatment levels (1,2 bar), the two degree of rotation treatments ( 0,90 degrees), and the two types of knifes (pointed, round) are chosen for the DoE. Table 1 shows the randomized measurement order in this works.

\subsection{Parameters observation}

A full factorial design of experiment was conducted. Randomized measurement order was generated by the software. Randomized trials were used to balance the uncontrolled effects thus reducing the chances that differences between all parameters biased strongly. The experiments were replicated one time in order to ensure the reliability of the data.

The characteristics of the specimens obtained from the experiment will be judged as shown in the figure 7 and figure 8. Characteristic A is that the workpiece is destroyed. Characteristic $\mathrm{B}$, the specimen is incomplete due to the inability to push the seeds out. Characteristics $\mathrm{C}$ is a good piece.

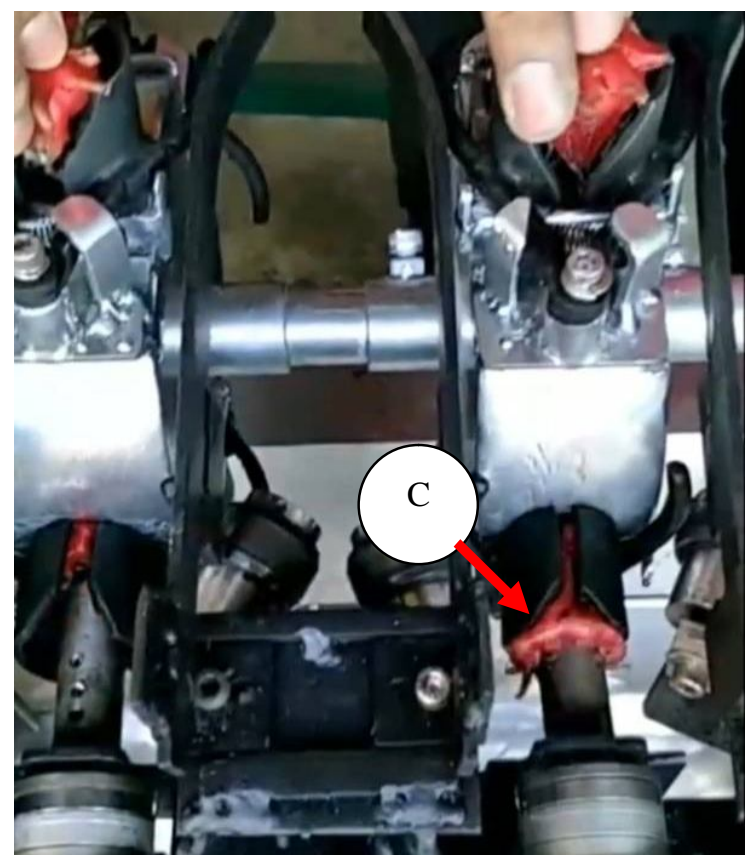

Figure 8: Judgment on outcome C 


\section{RESULTS AND ANALYSIS OF VARIANCE (ANOVA)}

The results obtained from experiments with 500 samples per experiment, after analysing it with the ANOVA, it was found that,

One-way ANOVA: Good versus Knife type

$\begin{array}{llllll}\text { Source } & \text { DF } & \text { SS } & \text { MS } & \text { F } & \text { P } \\ \text { Knife type } & 1 & 4128 & 4128 & 0.10 & 0.752 \\ \text { Error } & 14 & 556999 & 39786 & & \\ \text { Total } & 15 & 561127 & & & \end{array}$

$\mathrm{S}=199.5 \quad \mathrm{R}-\mathrm{Sq}=0.74 \% \quad \mathrm{R}-\mathrm{Sq}(\operatorname{adj})=0.00 \%$

One-way ANOVA: Good versus Rotation

$\begin{array}{llllll}\text { Source } & \text { DF } & \text { SS } & \text { MS } & \text { F } & \text { P } \\ \text { Rotation } & 1 & 92873 & 92873 & 2.78 & 0.118 \\ \text { Error } & 14 & 468254 & 33447 & & \\ \text { Total } & 15 & 561127 & & & \end{array}$

$\mathrm{S}=182.9 \quad \mathrm{R}-\mathrm{Sq}=16.55 \% \quad \mathrm{R}-\mathrm{Sq}(\operatorname{adj})=10.59 \%$

One-way ANOVA: Good versus Air pressure

$\begin{array}{llllll}\text { Source } & \text { DF } & \text { SS } & \text { MS } & \text { F } & \text { P } \\ \text { Air pressure } & 1 & 387195 & 387195 & 31.17 & 0.000 \\ \text { Error } & 14 & 173932 & 12424 & & \\ \text { Total } & 15 & 561127 & & & \end{array}$

$\mathrm{S}=111.5 \quad \mathrm{R}-\mathrm{Sq}=69.00 \% \quad \mathrm{R}-\mathrm{Sq}(\operatorname{adj})=66.79 \%$

The result of the factorial design analysis based on the rate of good pieces, type of knife with two treatment levels has the $P$-value equal to 0.752 . Since it is larger than $\alpha=0.05$, then we can conclude that it has no significant effects to the rate of good pieces. This matter indicates that we could generally use the knife with pointed or round type we will get the same outcome. As shown in figure 9, there were no significant differences in the rate of good pieces.

While the $P$-value of degree of rotation with two treatment levels equal to 0.118 which is also larger than $\alpha=0.05$ then we can also conclude that it has no significant effects to the rate of good pieces or may be considered almost significant as shown in figure 10 it was found that the slope was slightly higher than figure 9 .

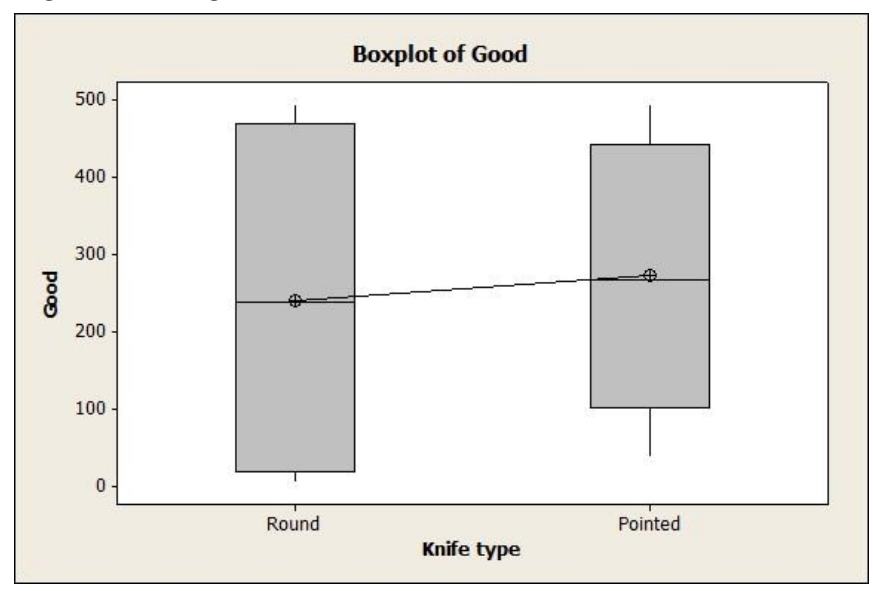

Figure 9: Boxplot of Knife Type vs Number of Good Pieces

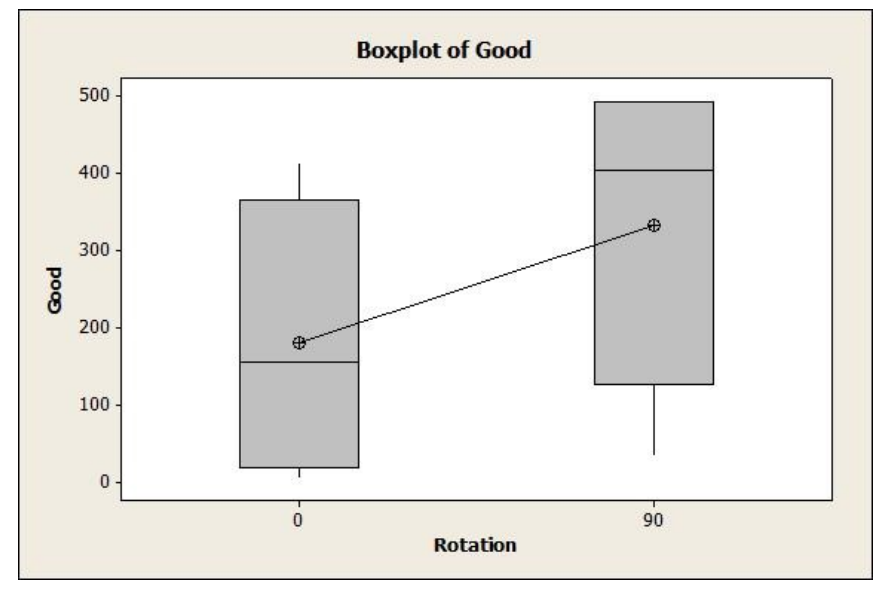

Figure 10: Boxplot of Degree of Rotation vs Number of Good Pieces

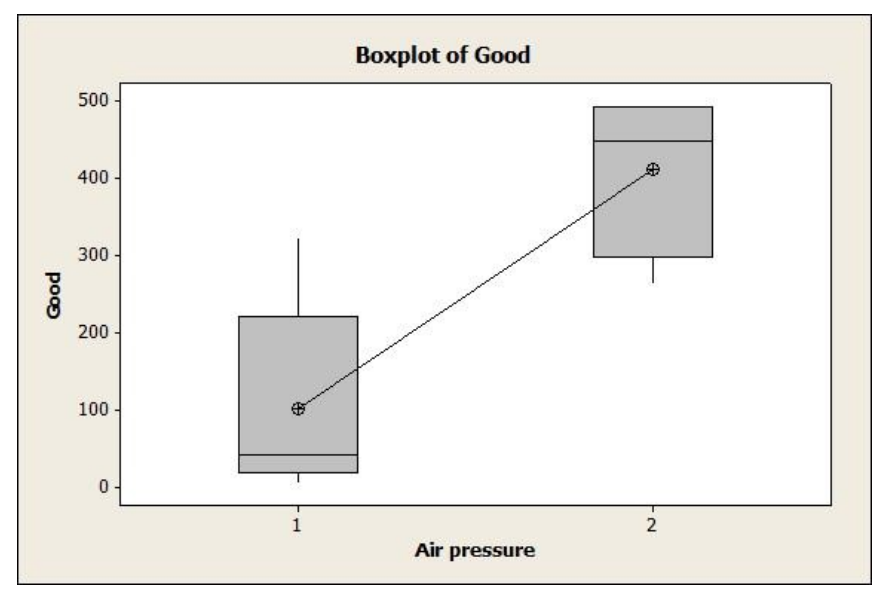

Figure 11: Boxplot of Air Pressure vs Number of Good Pieces

On the other hand, the air pressure with two treatment levels has $P$-value equal to zero, which is very much smaller than $\alpha=0.05$, thus explaining that it has a significant effect to the rate of good pieces. Figure 11 clearly shows the difference in 
slope when the air pressure is different, the rate of good pieces will be different.

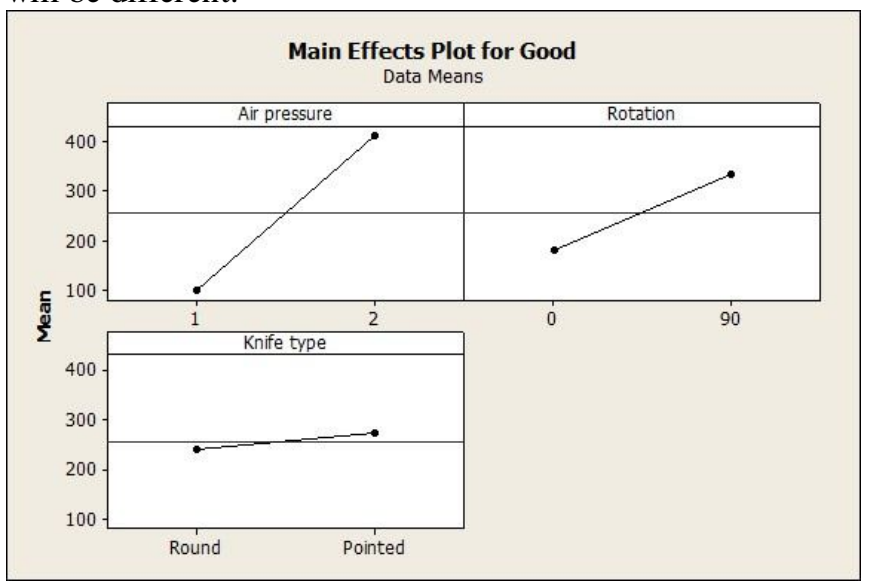

Figure 12: Main effects Plot vs Number of Good Pieces

Figure 12 compares the slope of the graph caused by the relationship of the main variables affecting the rate of good specimens. We can explain that, at a higher slope will have less $P$-value. Which means, that variable had a significant effect on the outcome.

\section{CONCLUSION}

Software-based project simulations help the researcher or machine design maker make confident decisions about how to design a proper machine. ANalysis Of Variance (ANOVA) is performed in order to investigate and identify the most significant parameter for the good yield of the roselle seed ripping production which is air pressure supplied. At the same time, the rotation of the knife is a variable that may be considered to be significantly inferior to the outcome. While the type of knife had no significant impact.

\section{ACKNOWLEDGEMENT}

This works is done thanks to suggestions and recommendations from Dr.Dechathanat Thongkot, who participant until the end of project completion.

\section{REFERENCES}

1. D. C. Montgomery. Design and Analysis of Experiments, John Wiley \& Sons, 2006.

2. L. Chen, Z. Liu, P. Sun, and W. Huo. Formulation of a fuel spray SMD model at atmospheric pressure using Design of Experiments (DoE), Fuel, vol. 153, pp. 355-360, Aug, 2015.

3. K.A. Soudki, E., F.EI Salakawy, and NB. Elkum. Full Factorial Design Optimization of Concrete Mix Design for Hot Climates, ASCE Journal of Materials in Civil, vol. 13, pp. 78-86, 2001.
4. Vijay Kumar Burugari, Prabha Selvaraj, Venkata Praneel, Hari Kishan Kondaveeti, M Pravin Kumar. The Application of Computational Modeling for the optimization of Bio Fuel Production Processes, International Journal of Advanced Trends in Computer Science and Engineering, Volume 9, No.5, pp.7883-7893, 2020.

5. Dana Salameh, Salah Abdallah. Design and Analysis of an Ergonomic-Automated Adjustable Drafting Table, International Journal of Advanced Trends in Computer Science and Engineering, Volume 9, No.4, pp.4352-4358, 2020.

6. Ledolter, J. and Swersey, A. Using a Fractional Factorial Design to Increase Direct Mail Response at Mother Jones Magazine, Vol.18. pp. 469-475, 2006.

7. Johnson, L. and Bell, G. Designed Experiments in Service Quality Applications, World Congress on Quality and Improvement, ASQ Conference, Minneapolis, MN, USA, May 18-20, 2009.

8. Goh, T.N. The Role of Statistical Design of Experiments in Six Sigma: Perspectives of a Practitioner, Quality Engineering, Vol.14, No.4, pp. 659-671, 2002.

9. Nurulhaida Bt Zakaria, Sharifah Sakinah Bt Syed Abd Mutalib, Mohamad Asyraf bin Mohd Am. Two-Factor Factorial Design to Identify the Best Combination of Factors for PSL Production, International Journal of Advanced Trends in Computer Science and Engineering, Volume 9, No.1.3, pp.128-131, 2020.

10. Zirawani Baharum, M. N. Taufiq Affandi, Azliza Yacob, Rafidah Ali. The Critical Factors for Built Up Edge Formation in Stainless Steel Milling, International Journal of Advanced Trends in Computer Science and Engineering, Volume 9, No.1.4, pp.282-288, 2020. 